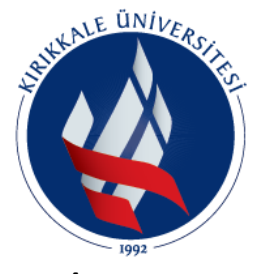

Cilt/Volume:10
MÜHENDISLIK FAKÜLTESI

Sayı/Issue:2

Haziran/June 2018

\section{Uluslararası Mühendislik Araştırma ve \\ Geliştirme Dergisi}

International Journal of Engineering

Research and Development

https://doi.org/10.29137/umagd.446803

Araştırma Makalesi / Research Article

\title{
Control of A Car, Via Internet
}

\begin{tabular}{|c|c|c|}
\hline \multicolumn{3}{|c|}{ 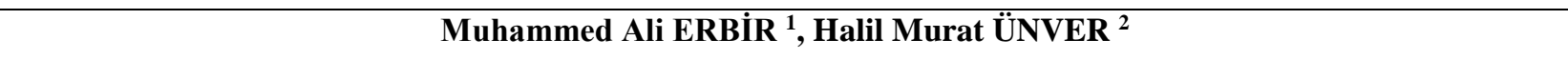 } \\
\hline \multicolumn{3}{|c|}{$\begin{array}{c}{ }^{1} \text { Kirlkkale University, Kirıkkale Vocational High School, Electric Department, TURKEY } \\
{ }^{2} \text { Kirlkkale University, Computer Engineering Department, TURKEY }\end{array}$} \\
\hline Başvuru/Received: 03/11/2017 & Kabul/Accepted: 02/06/2018 & Son Versiyon/Final Version: 29/06/2018 \\
\hline
\end{tabular}

\begin{abstract}
Internet and mobile devices such as phones, tablets, and even wearable goods are getting more popular day by day. Embedded system technology offers fast, cheap, and optimized solutions for designers with its wide portfolio. This study demonstrates a remote-control application of a car via internet platform. An embedded system was designed with an Arduino card to interact with the car hardware and an android application was developed to control the car. The car was controlled by the android application via an internet connected embedded system successfully.
\end{abstract}

\section{Key Words}

Control over Internet, Remote Car Control, Control by Arduino, Embedded Control System by Arduino, Arduino Remote Control 


\section{INTRODUCTION}

Necessity and demand for remote controlling increase significantly (Atabaş, Arslan et al. 2007). An unsuitable working environment for an operator (such as temperature, distance, sickness, absence of vital goods) forces people to use remote control systems. Nonetheless, not for only necessity, but also for easiness, comfort, fastness, practicality, people prefer remote controlling (Arabe 2001).

In this study, several possibilities to control a car over mobile internet were investigated in terms of economy, practicality, upgradeability. Hereby, designing an Arduino embedded circuit, controlling the hardware of an automobile with this circuit, and communicating with the system via internet were decided. An automobile was used as an experimental rig.

In an electronic system, electronic units communicate each other with wires or wirelessly depending on the requirements (Fielding, Meeks et al. 2000). Using wires is a cheap and non-sophisticated method. On the other hand, when wiring is not advantageous because of reasons such as distance, mobility, and ineligibility of transmission media, wireless technology is preferred (Fielding, Meeks et al. 2000). Various wireless technologies can be preferred according to the data transfer rate, distance, transfer medium, and transfer type criterion (Goldsmith 2005). IR communication, Bluetooth technology, cellular phone services, GPS, satellite communication, and even ultrasonic communication are some types of wireless communication techniques.

The Internet is a global system of machines that uses the Internet Protocol (IP) for communication (Forouzan and Fegan 2002). The Internet Protocol is a communication protocol that works with the idea of delivering data packages, from source to the destination host, using IP addresses encapsulated in the data packages. In the IP protocol, most of the hosts are registered to a local network with an IP address, some hosts and all networks are connected to the global system with a unique IP address. The IP communication technology is applicable on both wired and wireless media. ADSL and cabled ethernet are examples of IP application with wires. On the other hand, WLANs and cellular communication using $4 \mathrm{G}$ are examples of IP application wirelessly. In recent years, car internet connections are widely preferred. Real-time weather and traffic condition or other critical Information about the route of the vehicle may affect the decisions of drivers, related people and concerned supervisors from transport companies to official traffic organizers (Zhu, Zhang et al. 2011). This situation is a result of mobile internet technology that becomes more affordable and popular (Goggin 2012). Internet usage in vehicles is a new technical and social research topic (Sheller and Urry 2000). The internet usage can affect whole traffic flow in terms of density, speed, and stability in a positive way (Goggin 2012) (Jameel, Stuempfle et al. 1998). There are research studies performed on the effects of internet usage in transportation on agriculture, fishery, and other industry in term of marketing, prices, and transport costs (Donner, Gitau et al. 2011). Nowadays, İstanbul Municipality Public Transportation System actively uses internet connected vehicles., The estimated arrival times to bus stops of vehicles are shared publicly over internet via GPS information.

The term "computer" implies a general-purpose device that can be programmed to realize huge number of tasks. Moreover, some special computers, named as embedded systems, are designed to execute dedicated functions (Barrett 2009). They have their own hardware and software. ADSL modems, digital watches, car computers, GPS receivers are some examples of embedded systems.

Embedded systems are based on a microprocessor or microcontroller, input and output ports, and their own hardware. PIC microcontrollers by Microchip Technology Inc. and AVR microcontrollers by Atmel Corporation are famous ones for small scale embedded system designers.

Arduino, Raspberry Pi, and Beagle Bone are easy-to-use embedded system platforms. They have their own free compilers, libraries, and lots of examples. Arduino is the cheapest one and sufficient for this project. So that, Arduino was preferred as the platform.

Almost all internet services are reachable by users with web browsers and almost all personal computers such as desktops, laptops, tablets, and mobile phones can run various web browsers. In recent years, Android OS is getting 
more popular. Thus, in this paper, two interfaces are prepared. The system can be controlled via either a web browser or an Android device.

In this study, a control system that provides communication between user and his car with IP protocol was designed. An automobile was selected as a test platform. To control and communicate with automobile hardware an Arduino controller, an automatic engine starter module and some relays were employed. IP protocol was selected as the communication technology because it has many advantages and widely used in daily life. In order to control easily via almost all computers and mobile phones, two interfaces, HTML and Android application were prepared. System was applied on an ordinary automobile, and the test automobile was controlled successfully.

An embedded system shown in the Figure 1, was designed and mounted to the car. Hardware of the car is controlled via introducing proper signals to the relevant cables carrying control signals. Appropriate Arduino code was written. An IP camera was located in the car and involved in the car control system. By this way, both image and sound around and in the car became accessible. In the system, a 3G-WLAN gateway is used to reach the car via internet.

The developed system can be an economic, easily applicable, good solution for remote control of mobile machines and devices.

\section{REALIZING THE SYSTEM}

Following components are employed to realize the system:

- Arduino mega controller card,

- Arduino ethernet shield (module),

- 8-channel relay set

- Wireless access point

- Ethernet cable and simple conductor cable

- Breadboard

- A computer

- Arduino and Android compilers

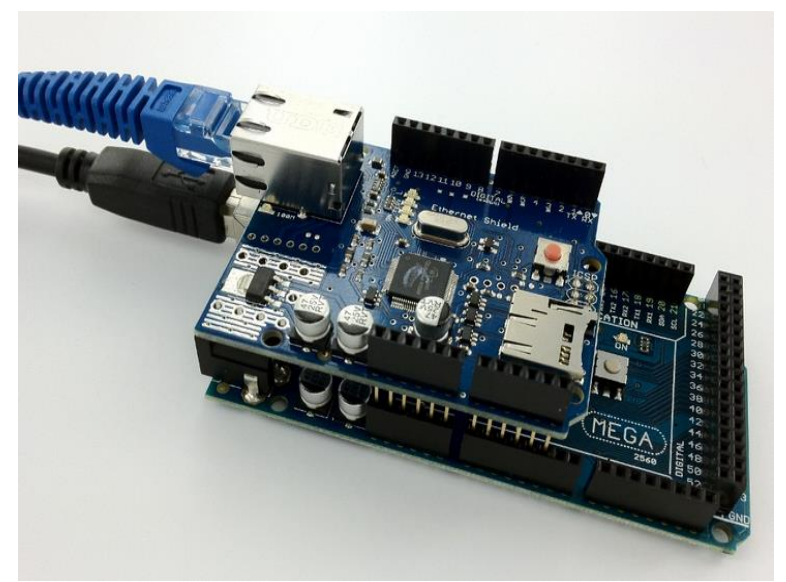

Figure 1: Arduino ethernet shield over Arduino mega

An Arduino controller with an ethernet shield is the main component of the project. Arduino Mega was selected as the controller because:

- It is cheaper and easier to use than its alternatives, such as raspberry pi, BeagleBone

- It has large libraries,

- It has a wide market,

- It needs little cabling,

- It can communicate to PC and compiler directly, it does not need a programmer device like a pure microcontroller, 
- It can communicate to a PC while running, unlike a PLC

- Arduino MEGA has 78 pins can be assigned as inputs or outputs,

Ethernet shield is a tool to communicate with others using IP protocol. Arduino was connected to the wireless access point shown in the figure 2, with an ethernet cable. It was possible to connect the Arduino to the access point with a Wi-Fi shield, but it's more expensive than the cabled ethernet shield. A cheaper solution (wired ethernet) was preferred because the Arduino and the access point were placed adjacently, and cabling was easy. Another disadvantage is the start-up time of the Wi-Fi shield is six times longer than the cabled ethernet shield.

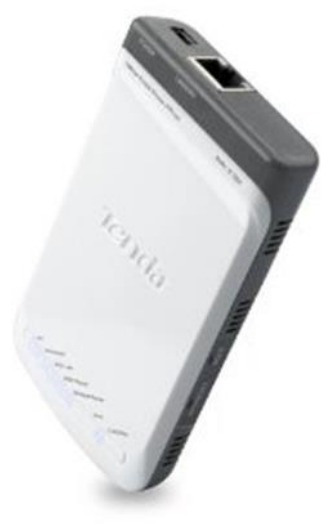

Figure 2: wireless access point device

A WLAN nearby the car is created and the system is connected to the Internet by the wireless access point. The system is reachable via WLAN up to 200 meters. Farther users can reach via the Internet. The system was connected to the Internet via a $3 \mathrm{G}-\mathrm{Wi}-\mathrm{Fi}$ gateway supplied by the Turkcell company.

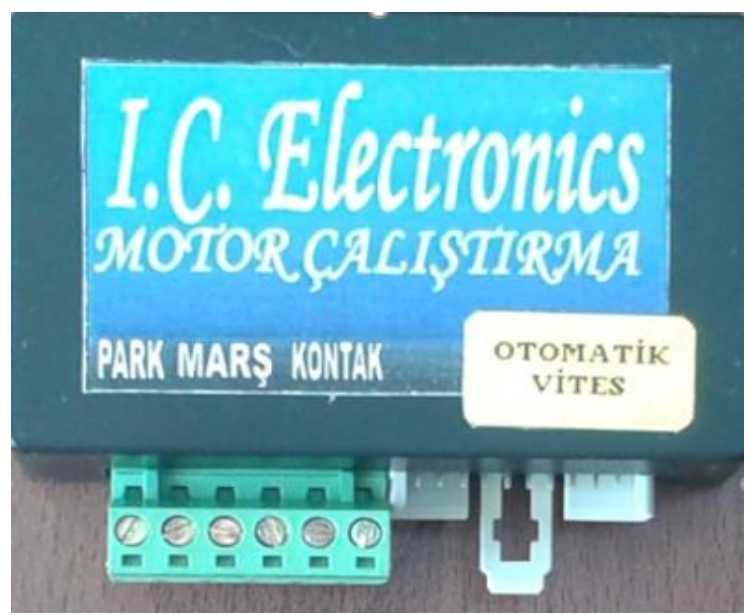

Figure 3: an engine auto start-stop module

An automatic engine starter module shown in the Figure 3, was employed to start and stop the engine with a signal by the controller. When a request arrives to Arduino, it triggers the module to start the engine. 


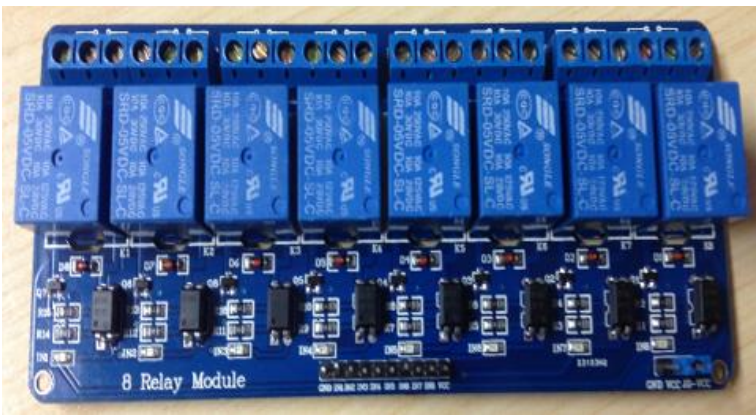

Figure4: An 8-channel relay module

Some relays, shown in the figure 4, are employed to activate, deactivate or trigger the hardware of the car.

IP protocol has advantages such as; can be used both wired and wirelessly, being cheap and practical, able to be connected by devices widely used in daily life. That's why, IP protocol communication technology was selected in the system.

In order to be controlled easily via almost all computers and mobile phones, two interfaces, an HTML service web page and an Android application were prepared.

System was applied on an ordinary automobile, a Honda Jazz 2004. Door locks, headlights, signals, horn and motor situation of the test automobile was controlled successfully. When the controller receives a request from a user, it interprets the demand. It decides what to do, which hardware to manage, and how to send the signal.

A server code is prepared and loaded into the embedded system. A screenshot is given in the figure 5. Free Arduino compiler is used for embedded programming.

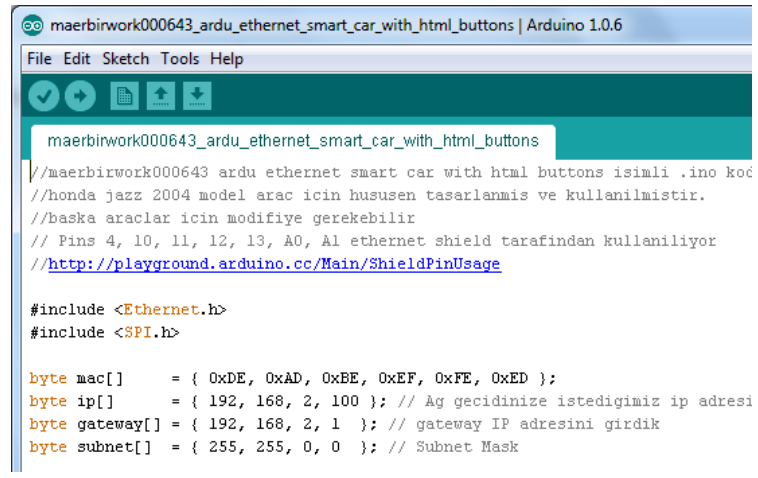

Figure 5: Arduino compiler window

A static IP address was assigned to the controller for enabling users to easily reach the controller system. In LAN, by using the local static IP, users can reach the controller directly. From the internet, users reach external side of the 3G to Wi-Fi gateway with a specific port number. The connection through that port is forwarded to the local IP of the controller by the gateway. Port forwarding settings of the gateway is given in the Figure 6.

virtual server list

\begin{tabular}{cccccc} 
name & $\begin{array}{c}\text { WaN Conn } \\
\text { Point }\end{array}$ & $\begin{array}{c}\text { LAN } \\
\text { IP Address }\end{array}$ & $\begin{array}{c}\text { LAN } \\
\text { Conn Point }\end{array}$ & Protocol & Situation \\
\hline smart_car & 1000 & 192.168 .2 .100 & 80 & TCP/NDP & Open \\
smart_office & 1001 & 192.168 .2 .101 & 80 & TCPNDP & Open
\end{tabular}

Figure 6: IP forwarding table on the gateway 
An html web server code was embedded into the controller. Thus, users can easily reach and control the system using any device, which is running a web browser.

On the other hand, the system can be controlled via the Android application designed during this project. A screenshot of the android code script is shown in the Figure 7.

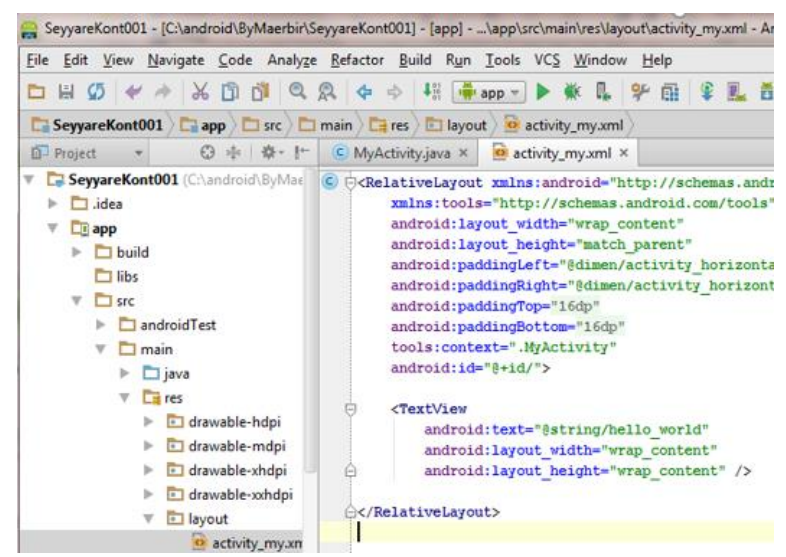

Figure 7: Android compiler window

In the application window, left part is the information display and right part contains the control buttons. In the display, users can view the current situation of car hardware such as motor is running, headlights are turned off etc. Buttons are employed to send commands to the controller. A screenshot of the android application is given in the figure 8 .

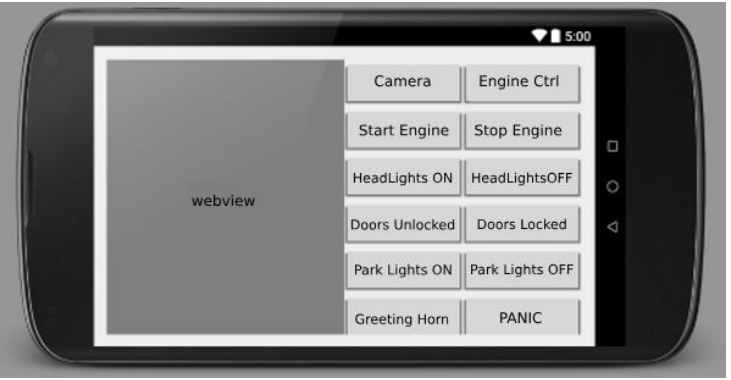

Figure 8: design of the Android application

An IP camera was in the car and involved in the car control system with a static IP.

Total expenditure for the project is given in the Table 1 listed below.

Table 1. Cost of the project

\begin{tabular}{|c|c|c|c|}
\hline components & Unit price & pieces & total \\
\hline Arduino Mega & $45.55 \$$ & 1 & $45.55 \$$ \\
\hline Ethernet shield & $16.56 \$$ & 1 & $16.56 \$$ \\
\hline Breadboard & $4.14 \$$ & 5 & $20.70 \$$ \\
\hline Wi-Fi access point & $24.84 \$$ & 1 & $24.84 \$$ \\
\hline Jumper cables & $19.35 \$$ & 1 & $19.35 \$$ \\
\hline Circuit box 24” & $7.87 \$$ & 1 & $7.87 \$$ \\
\hline Circuit box 10" & $5.80 \$$ & 1 & $5.80 \$$ \\
\hline Auto-starter module & $24.84 \$$ & 1 & $24.84 \$$ \\
\hline 8-channel relay set & $13.25 \$$ & 1 & $13.25 \$$ \\
\hline
\end{tabular}


Table 1. (Cont) Cost of the project

\begin{tabular}{|c|c|c|c|}
\hline $\begin{array}{l}3 \times 1.5 \mathrm{~mm} \text { conductor } \\
\text { cable }\end{array}$ & $4.14 \$$ & 3 & $12.42 \$$ \\
\hline 3G-Wi-Fi Gateway & $21.95 \$$ & 1 & $21.95 \$$ \\
\hline \multicolumn{3}{|c|}{$\begin{array}{l}\text { An android device or any device that can run a } \\
\text { web browser to control }\end{array}$} & - \\
\hline Grand Total (\$) & & & $213.13 \$$ \\
\hline
\end{tabular}

\section{RESULTS AND DISCUSSION}

The system developed in this study can be a good, economic, easily applicable solution for remote control of mobile machines and devices. System components can be connected and programmed manually without a professional laboratory environment. The components that are used in the project are easily affordable and easy to obtain. Total cost is 213 dollars. The software used in the project are open source. Relays are used to control the hardware of the car. Ethernet and the Internet are used in the project, which are free, and widely used in the world.

The points mentioned above results that the project is easily applied on any remote-control application. Moreover, it can answer a wide range of remote control needs with its extensive capabilities, and low cost.

\section{REFERENCES}

Arabe, K. C. (2001). "Remote Control: Material Handling at a Distance." ThomasNet News INDUSTRY MARKET TRENDS.

Atabaş, İ., M. Arslan and İ. Uzun (2007). "Isıtma Sistemlerinin Otomasyonu ve İnternet Üzerinden Kontrolü." $\underline{\text { IX. }}$ Akademik Bilișim Konferansı, Kütahya 31.

Barrett, S. (2009). Embedded System Design with the Atmel AVR Microcontroller, Morgan \& Claypool Publishers.

Donner, J., S. Gitau and G. Marsden (2011). "Exploring mobile-only Internet use: Results of a training study in urban South Africa." International Journal of Communication 5: 24.

Fielding, R., G. Meeks and P. Nair (2000). "Wired Versus Wireless."

Forouzan, B. A. and S. C. Fegan (2002). TCP/IP protocol suite, McGraw-Hill Higher Education.

Goggin, G. (2012). "Driving the internet: mobile internets, cars, and the social." Future Internet 4(1): 306-321.

Goldsmith, A. (2005). Wireless communications, Cambridge university press.

Jameel, A., M. Stuempfle, D. Jiang and A. Fuchs (1998). "Web on wheels: Toward internet-enabled cars." Computer 31(1): 69-76.

Sheller, M. and J. Urry (2000). "The city and the car." International journal of urban and regional research 24(4): 737 757.

Zhu, Z., L. Zhang and R. Wakikawa (2011). "Supporting mobility for internet cars." IEEE Communications Magazine 49(5). 